\title{
RISK MANAGEMENT LESSONS FROM THE FINANCIAL CRISIS: A TEXTUAL ANALYSIS OF THE FINANCIAL CRISIS INQUIRY COMMISSION'S REPORT
}

\author{
Corey J. Fox \\ Texas State University • San Marcos, TX
}

\section{ABSTRACT}

There have been several retrospective analyses of the financial crisis. An area that continues to receive attention is the failure of risk management in financial firms at the heart of the crisis. After the crisis, the United States Government convened the Financial Crisis Inquiry Commission to explore causes of the crisis. Their conclusions have gone largely unexplored, especially in academic research. In this study, I first examine the commission's report on the crisis identifying several reappearing themes. An exploratory follow-up analysis looking at financial and nonfinancial firms suggests non-financial firms have areas to improve upon compared to their financial counterparts.

Keywords: Financial crisis; Risk management; Risk management failure; Financial Crisis Inquiry Commission; FCIC

"Those who cannot remember the past are condemned to repeat it." - George Santayana (Philosopher)

\section{INTRODUCTION}

The financial crisis of 2008 and 2009 was the worst financial disaster to hit the United States in over seven decades. Organizations of all types were impacted as the events in the financial industry rippled throughout the economy. The crisis left the economy in shambles, dissolved trillions of dollars in wealth, and left millions of people without jobs and homes (Financial Crisis Inquiry Commission [FCIC], 2011). There have been many opinions about what the root causes of the crisis were (Jickling, 2009). While some recent research has suggested that excessive investment in financial products (both ordinary and exotic) were a considerable culprit (e.g., Tuckman, 2016; Vo, 2015) there has been much less work focused on the impact that risk management failures at the managerial level had on failing financial firms (e.g., Hubbard, 2009).

In 2009, the U.S. Government commissioned a committee to look into the 
causes of the financial crisis. This committee, known as the Financial Crisis Inquiry Commission (FCIC), gathered and analyzed a myriad of data before putting out a complete report based upon their extensive analysis, outlining what it believed to be the main causes of the crisis. While this report was made public, there has been little exploration or discussion of the findings in academic circles (per mention in academic research papers) especially as it relates to risk management within organizations. This is unfortunate since the report is built upon a vast amount of information and has implications for management practices related to the management of risk.

As suggested by the quote above from George Santayana, it is thought that finding a cause(s) can help businesses learn, and hopefully avoid, making the same (or similar) mistakes in the future. The purpose of this paper is to look, qualitatively, at the commission's in-depth report, analyze the passages around risk management and discuss the implications of the findings. Additionally, this paper explores whether financial and non-financial firms have learned from the failures identified in the commission's report.

The purpose behind expanding the study beyond just the large financial firms associated with the crisis, was to assess the degree of learning (if any) at other large, visible firms. The organizational learning literature (Huber, 1991; Madsen and Desai, 2010) has suggested that firms can make adaptations to its business operations and strategy as a result of reflections on their own experiences (experiential learning) or the experiences of others (vicarious learning). Financial institutions that were at the center of the crisis (such as the large financial firms and large regional banks) should be most likely to have made adaptations post crisis. However, we might also expect that other large, visible firms would make adaptations due in part to what they learned from the failings of these financial firms. However, the changes may be less pronounced since those firms were further away from the actual learning event.

In doing so, this paper makes three important contributions to the extant literature in risk management and organization studies. First, this paper adds to what is currently known about risk management failure, and more specifically risk management failure during the financial crisis. While much has been made about the failure of complex quantitative risk management systems, less is known about managerial-level failures. Second, this paper synthesizes and condenses a broad array of disparate statements in the FCIC report on risk management during the crisis into a small set of important risk management issues. These issues are described and discussed in detail so that managers and organizations (in all industries) can learn from the mistakes of these failed institutions. Last, there are prescriptive remedies given to help companies avoid risk management failures in the future. 


\section{RESEARCH BACKGROUND}

\section{The Commission}

Following the financial crisis, the US government convened a commission known as the Financial Crisis Inquiry Commission (FCIC) ${ }^{1}$, to examine the causes of the crisis. The FCIC was commissioned by the Fraud Enforcement and Recovery Act of 2009 and tasked with conducting a thorough investigation into the causes of the financial and crisis. ${ }^{2}$ The commission worked together for over 18 months gathering data from a multitude of sources and conducting interviews with people involved at various stages and levels of the crisis. Over that time frame, the commission scoured over millions of pages of documents, including the work of journalists, academics and other published sources. The commission interviewed more than 700 material 'witnesses' and conducted numerous public hearings across the country in an attempt to learn about what happened. Despite the widely held belief amongst industry regulators that financial firms were prudent risk managers with sophisticated financial models who had strong 'market' incentives to undertake sound risk management practices, the risk management systems at these large firms failed.

Risk management, like strategic management, is a process directed by the top managers of a firm during strategy formulation (Chapman, 2011). Risk management is generally described as an iterative, holistic process whereby firms identify, analyze, strategize, treat and communicate risks (Chapman, 2011; Frame, 2003; Shenkir, Barton and Walker, 2010; Shortreed, 2010). During the financial crisis, for many financial firms, there was a breakdown in the process. As a result, the following research questions were explored in this paper:

1) What were the contributing factors that led to financial firms' risk management failures during the crisis?

2) Post crisis, have firms (both financial and non-financial) learned from these failures?

\section{METHODOLOGY}

To explore the research objectives identified, I conducted two studies. In Study 1, I pursued a textual approach research methodology. The textual approach 
examines texts to gain insights about events. This research approach has been used before to make sense of events surrounding situations of crisis (e.g. Gephart, 1993). The purpose of Study 1 was to examine where the breakdown in risk management occurred at the large financial institutions who were at the heart of the crisis. In Study 2, I pursued an exploratory analysis where four separate types of firms were identified - large financial institutions, large regional banks, large non-financial companies with a dedicated financial services business segment, and large nonfinancial companies without a dedicated financial services business. For each group identified, three representative firms were chosen and a textual analysis of these firms' proxy statements from before and after the crisis was undertaken. The purpose of Study 2 was to examine whether financial and non-financial firms had learned from the failures identified in Study 1.

\section{Study 1}

First, I downloaded the entire FCIC report from the FCIC website (cited in the reference section). To find passages that were about risk management, I searched the text document for the phrase 'risk manage' which would catch any reference to risk management or risk manager. I also searched for two other variants of risk management by searching for 'managing risk' and 'manage risk.' In total, there were roughly 103 instances in the body of the main report of 410 pages. A graduate assistant and I parsed these instances and pulled out the surrounding sentences to create a list of passages. Of the 103 passages initially identified, 34 of the passages (33\%) were identified as containing no substantive or relevant information to address the research question. Appendix A has several examples of these passages, all of which were excluded from consideration. An additional 30 passages (29\%) discussed other influences of risk management failures beyond the scope of this study. For instance, information about regulators or the institutional environment were outside the boundary of the firm and thus subsequently excluded. The remaining 39 passages (38\%) were related to risk management inside the financial firms so were used for the analysis.

The assistant and I looked for themes in each of the passages. After initial analysis and conversations, five sources of failure emerged. The first category was classified as Risk Management Process Failures. This category included any mention of problems related to risk assessment, risk evaluation and analysis, risk treatment, or risk communication. This category also included any mention of problems with the firms existing risk management protocols. The second category 
was classified as Support System Failures (Compensation). This category consisted of passages showing failures in the firm's compensation system which may have had an impact on risk behavior. The third category was classified as Resource Allocation Failures. This category included any passage that described the human or financial resources allocated to support the risk management function. The fourth category was called Top Management Failures. This category focused on failures created by top management overconfidence and hubris. The fifth and final category was called Objective Tradeoff Failures. This category consisted of passages focusing on the tradeoffs made between risk and financial objectives.

To validate the categories and the correct assignment of passages to categories, six undergraduate students, majoring in Finance with a concentration in Insurance and Risk Management at a large Midwestern university, volunteered to participate in exchange for extra credit. The students were randomly given between 12 and 14 passages where each passage was evaluated by two students. In addition to the passage, students were given the category titles and a description of each category. In addition to the five categories mentioned above, an Other category was also included if the student thought the passage did not belong in any of the categories. Each student was instructed to place the passage into the category which they felt best described the passage. While it is certainly possible that some of the categories could indeed be related with one another (for instance, compensation systems might impact whether a firm focuses on performance metrics or risk management outcomes), the purpose was to validate the themes surrounding risk management according to the FCIC report (i.e., what appeared most often). Across the six volunteers, agreement was obtained just over $73 \%$ of the time. There were four passages in which both students failed to classify the passage according to one of the pre-specified categories. These passages were omitted from consideration, leaving 35 total passages. Any remaining passages where at least one student classified the passage according to the pre-specified categories and another did not, were resolved through discussion.

\section{Results}

After the analysis was complete the passages were explored in relation to the five general themes which had emerged. Below is a discussion of each general theme, each of which is supported with reference to several representative passages which provided information to identify the theme. Several of the themes are similar in nature and could be interpreted as being from relatively similar sources, however 
an effort was made to try and segment the themes to be as fine-grained as possible. All of the supporting passages discussed can be found in Appendix A under the appropriate heading. ${ }^{3}$

Risk management process failures. The most often mentioned failure found in the report points to a general failure of the risk management process in financial firms. The risk management process, according to literature in finance and strategic management, is generally conceived of as a holistic approach spanning the entire organization (e.g., Clarke and Varma, 1999; Fraser and Simkins, 2010; Miller, 1998; Miller and Waller, 2003) and has been referred to by various names like Enterprise (ERM), Integrated (IRM) or Strategic (SRM) risk management. This process generally includes risk identification, assessment, evaluation, treatment, review and communication (Chapman, 2011). Passages within the report suggest that there were breakdowns in each of these areas in addition to using a holistic approach.

During the financial crisis, firms were still subscribing to the antiquated 'silo' approach to risk management. The first general problem was that risks were being managed independent of one another without much information sharing across business lines. There is evidence of this shown in Passage 1 where Citigroup's risk management function was operating independently along each of its separate business lines. Employees just steps away from each other, working with similar risk assets, or risk products which were related, did not know what each other were doing. Information that was gained from each business line with respect to the risk assets was being kept away from other sources that could potentially benefit from such information.

A second area of concern was with the risk identification, assessment, evaluation and treatment process. For instance, as suggested in Passage $2 \& 3$, risk managers were not able to properly identify soft risks. Soft risks are those which require judgment and are not purely financial in nature. In too many instances, instead of using judgment, managers were using mathematical models as predictors for risks. Furthermore, the models being used to determine which risks should be managed were based on assumptions that were markedly wrong. There was little evidence of scenario planning in assessing the probabilities and worst case scenarios for home price declines. Lastly, as evidenced by additional passages, managers were comfortable using financial hedges as effective treatment strategies since it had the added benefit of reducing the amount of financial slack the firm had to hold.

A third problem related to risk management processes was risk communication. Risk communication involves communication and consultation 
between management and the individuals/departments responsible for implementing and carrying out the risk management strategy to make it more effective over time (Chapman, 2011). Prior research has found that having communication links between the governing parties of the organization and those in charge of risk management can increase efficiency and firm performance (Grace, Leverty, Phillips and Shimpi, 2015). During the crisis it was evident that in some firms, communication between the management team and the risk management department/team was less than ideal. In Passage 4 for instance, the executive committee at Lehman Brothers failed to include the company's Chief Risk Officer in decisions that directly impacted the risk of the firm.

Finally, in some cases, the entire risk management process was inadequate and lacking. In one passage, a consultant hired to examine Bear Stearn's risk management process was highly critical suggesting that key elements in the process, such as risk identification and assessment, were infrequent. He continued that the risk management function did not have the resources it needed (as discussed in more detail below) and was of a low priority to the firm.

Support system failures (Compensation). One of the most common systems for supporting goals and strategic decisions in organizations is the compensation system. In the management literature, executive compensation is a tool often used to align management interests with the interests of the firm's owners. Scholars in the risk management arena have similarly concluded that one way to focus management's attention on risk management is to align their compensation with risk management objectives and outcomes (Lam, 2014). Firms must reward risk management behavior through incentive structures which align good risk management practices with pay. Indeed, Grace and colleagues (2015) found evidence that firm performance was enhanced when compensation was aligned with risk management.

There are numerous instances in the report which suggest that several of the failed financial firms were not incentivizing good risk management, and instead were incentivizing more risky, short-term oriented behavior. Passages 5 through 7 highlight this notion. For instance, the head of the Federal Deposit Insurance Corporation (FDIC) remarked that incentives favored short-term risk-taking and profits over long-term risk considerations, sustainability and solvency. Lam (2014) has suggested that incentivized performance can be problematic for risk management when incentives are one dimensional -- they focus on a single, bottom-line figure.

At the time of the crisis, financial firms, in particular, tied aggressive pay packages filled with stock options to the price of the firm's stock. In many situations, the options granted to executives came with accelerated payouts. In 2006, one year 
before the onset of the company's demise, Merrill Lynch CEO Stanley O'Neal made $\$ 91$ million. When he walked away from the company as it began its decline he left with a total consolation package of \$161 million (Farrell and Hansen, 2009). Richard Fuld, CEO of Lehman Brothers, was awarded \$34 million before he departed. These kinds of pay structures, littered with stock options, created incentives to increase the amount of risk executives took to improve returns. This included greater leverage levels and, in some cases (e.g. Frannie and Freddie), fraudulent financial filings. Indeed, academic research has argued that executives at Bear Stearns and Lehman Brothers in particular, had incentives to take on large amounts of risk as they had already pulled out hundreds of millions of dollars in options and bonuses prior to the collapse (Bebchuk, Cohen and Spamann, 2010).

Resource allocation failures. One of the pre-requisites for successful risk management is the allocation of necessary resources to adequately perform the job. Depending upon the size of the organization and the scope of the risk management system (and goals for the system), the two most critical resources are human and financial capital. Firms need to have staff ready to engage with the risk management process, and depending upon the risk management strategies developed, the risk management staff needs the appropriate amount of capital to execute the strategy. During the financial crisis, the FCIC report alludes to both elements lacking.

In terms of inadequate personnel, the auditors of several of the failed firms were critical of the firms' appointed risk managers. This included managers hired to lead the risk management departments. For instance in Passage 8, the auditors of AIG raised concerns about the skill sets of the top management team (CEO, $\mathrm{CFO}$ and $\mathrm{CRO}$ ) and managers appointed to the ERM department concerning their capacity to do the job of managing risk. Also, in Passage 9, the SEC criticized Bear Stearns because their risk management functions lacked expertise in the risky products they were supposed to manage the risk, and the risk management function was understaffed.

In addition to personnel, financial resources were also inadequate. Firms withheld, and sometimes cut, the resources for the risk management departments to do their jobs. For example, Passage 10 exhibits a willingness by management to tell the board of directors at Fannie Mae that risk management had all necessary resources to act on risk management initiatives. However, the CRO disagreed as his department saw double digit budget cuts which led to a reduction in head count in the year leading up to the crisis.

Top management failures. Many of the failures in risk management during the crisis can be traced back to failures at the top of the firm and with each 
firms' corporate governance. In the management literature, the upper echelon's perspective (Hambrick and Mason, 1984) suggests that firms are a reflection of its top management team as well as those in charge of setting the strategic direction of the firm. In the case of the financial crisis, top management teams were seen as a major reason why some firms had failed. Indeed, in testimony to the FCIC, J.P. Morgan CEO Jamie Dimon, one of the firms that survived the crisis, suggested that top management teams were to blame for the problems at the failed financial institutions and nobody else.

Another cause of risk management failure during the financial crisis was managerial hubris concerning risk management competencies. Hubris refers to an extreme level of pride or overconfidence in one's self and abilities. Hubris has been associated with a number of corporate maladies including overpaying for acquisitions (Hayward and Hambrick, 1997) and corporate social irresponsibility (Tang, Qian, Chen and Shen, 2014). Related to hubris, the overconfidence bias is the tendency for a person to have greater subjective confidence in their judgment or abilities than is objectively warranted. In many of the failed financial firms, the top management teams were very confident about the effectiveness and adequacies of their risk management systems. Numerous CEOs had made mention of their risk management competencies even though none had necessarily been tested in remotely turbulent market environments. For instance, in Passages 4,11 \& 12 the CEOs of Lehman Brothers, AIG and Merrill Lynch touted their risk management programs, going so far as to suggest that their risk management programs were strong and a fundamental component of their business model.

Two potential reasons are apparent from the report which may have resulted in executive hubris. First, the resilience of the big financial institutions to avoid big losses in prior debacles, like the dot com bubble, led managers and firms to believe they had robust and successful risk management systems in place. Second, hubris may have resulted from misplaced overconfidence in the complex mathematical models used for assessing risk. Financial institutions were lulled into a false sense of security as these models would show that financial firms had little to be concerned about, and which up to that point, had kept the firms safe. In some instances, the complex models had even given the firms' auditors reason to believe that risk had been reduced or eliminated. As an example, in Passage 13, AIG's auditors were convinced that the firm's economic risks were essentially zero. Thus, the models appeared to have been a contributing factor to executive hubris. Auditors and CEOs were not alone in their false sense of security. Regulators and industry experts like Fed Chairman Greenspan at the time, also believed the sophisticated modeling 
techniques would protect financial firms from disaster.

One might also consider that while cognitive bias appeared present, the other themes addressed herein are also the domain of top managers. Thus, while top management failures are highlighted as a function of managerial cognition, the other elements of failure are also reflections of decisions made by members of the top management team at the financial firms.

Objective tradeoff failures. The final contributing factor from the analysis suggests that some firms were faced with a difficult tradeoff between, what were framed as, mutually exclusive choices. The firms could either do the right thing from a risk management perspective or pursue strategies that advanced the goals and aspirations of the firm -- but not both. For instance, in Passage 14, there is clear indication that management at some firms, including Fannie Mae, were pursuing strategies that increased their firm's level of risk while in pursuit of corporate objectives but which ran counter to good risk management practices. Additionally, some objectives and aspirations encompassed by corporate initiatives like growth, played a role in some decisions by risk management departments to loosen the reign on risk appetite. As mentioned in Passage 15, Citigroup allowed risk management departments to approve higher risk limits if a business line was growing.

Study 1 conclusions. To sum up, the analysis of the FCIC report seems to support five areas of risk management failure during the financial crisis. First, there were failures in the risk management process and the use of holistic risk management models. Second, systems (more specifically, compensation systems) that should support the risk management process and promote risk management thinking, were not constructed properly. Third, the necessary human and financial resources to properly support effective risk management functions were not provided. Fourth, top management hubris created a false sense of confidence in the existing risk management systems. Finally, firms were faced with a false choice between managing risk properly and achieving the bottom line objectives of the company. All of these issues, combined, led to an environment where risk management was likely to be less than adequate to deal with the challenges presented by the financial crisis.

\section{Study 2}

In study two, I wanted to explore some of the conclusions of study one in more detail and probe whether firms, both in and outside of the financial industry, had addressed the shortcomings which led to the failure of risk management. As such, study two was an exploratory study - a first step, in assessing pre and post crisis firm 
behavior. Firms were segmented into four categories, each more removed from the center of the crisis. I started by identifying a representative set of three firms for each of the following four categories. The categories and representative firms were: large financial firms (J.P. Morgan Chase (JPM), Bank of America (BAC), Wells Fargo (WFC)), large regional banks (SunTrust Banks (STI), BB\&T Corp (BBT), Fifth Third Bancorp (FITB)), large non-financial firms which had a dedicated financial services business segment (General Electric (GE), Ford Motor Company (F), Deere \& Co (DE)), and large non-financial firms which did not have a dedicated financial services business segment (Nike (NKE), Proctor \& Gamble (PG), The Coca-Cola Company (KO)).

For each firm, proxy statements filed before the crisis (2005-2007) and after the crisis (2010-2012) were pulled from the SEC website. Each of the proxy statements was examined using a basic text analysis. I calculated averages for both sets of data so that I could get a more accurate picture of each firm's situation before and after the crisis. In study two, I looked at four things related to study one. First, related to the use of a holistic risk management program, I looked at how often the terms 'risk manage,' or some variant of 'manage risk', were used in the proxy statement. Second, I looked for evidence that the appropriate human resources were allocated to risk management by searching for someone with a title who was designated as someone in charge of managing risk (e.g., Chief Risk Officer (CRO), risk executive, or risk manager). Third, related to the focus of compensation design, I looked for how prevalent risk and risk management were in a company's discussion of executive compensation. Last, I explored the prevalence of 'growth' and 'return' in the proxy statements compared to the use of the word 'risk' as this may relate to the trade-off between risk and the firm's bottom line. In this last part of the analysis, I made sure to only count the word 'risk' when it was not in reference to anything risk management-related. The use of word counts, as proxies for the level of importance of a theme or idea, has been described in prior qualitative methods research (e.g., Carley, 1993; Duriau, Reger, \& Pfarrer, 2007) and used in strategic management research (e.g., Angriawan \& Abebe, 2011).

\section{Results}

In regards to the use of a holistic risk management process, I searched for the phrase "risk management" and other variants (e.g., manage risk) to proxy for the importance of a formal risk management process. The number of instances were counted for each company and the results are displayed in Figure 1. The following 
observations can be made when looking at the data. First, risk management was rarely discussed in the proxy documents before the crisis across all types of firms, whereas after the crisis, risk management appeared much more frequently. Second, financial institutions and regional banks - those closest to the crisis, used the phrase more than non-financial companies (as much as two to four times more). After the crisis, financial institutions used the term more than any other type of firm while non-financial firms without dedicated financial services business segments used the term the least (on average). This result is consistent with the findings of the FCIC that described pre-crisis behavior related to risk management. While aftercrisis behavior regarding risk management seems to have improved, the relatively infrequent mention of risk management in non-financial firms is troubling.

With regards to human resource allocation, I searched the proxy statement for evidence that the firms had a dedicated executive or manager who was responsible for risk oversight. It was important that risk oversight was governed by someone within the firm as opposed to a committee on the Board of Directors. Search terms such as 'chief risk,' 'risk executive,' and 'risk manager' were used to capture titles which designate a position dedicated to risk oversight. Prior work in the risk management literature have used similar search terms as proxies for evidence of risk management programs and risk management implementation. For instance, Liebenberg \& Hoyt (2003) uses the presence/absence of a Chief Risk Officer (CRO) as a proxy to identify a firm's adoption of enterprise risk management. Similarly, Hoyt \& Liebenberg (2011) use the CRO as a proxy for risk management implementation. Along these lines, Beasley and colleagues (2005) identifies the CRO and other high level risk managers as champions of risk management, thus suggesting that these human resources are necessary resources for successful risk management.

The following observation was made from this qualitative search. ${ }^{4}$ Before the crisis, two of the financial institutions and two of the regional banks had a chief risk officer (although one of the regional banks only mentions the CRO in 2005 but not 2006 or 2007), while none of the non-financial companies had one before the crisis. After the crisis, all of the financial institutions and regional banks had appointed an individual as the head of risk oversight, while only one non-financial company had done so. However, the non-financial company that appointed a CRO had a financeoriented business segment. This result is in-line with the FCIC report in that before the crisis, most financial firms had not allocated the appropriate human resources to risk management. Here too it seems troubling that non-financial companies have not followed in the footsteps of their financial counterparts and appointed an individual with a risk designation. 
The third aspect of study one examined was the integration of risk management outcomes and processes in compensation design. To explore this, each company's compensation discussion section in the proxy statement was examined. Of particular interest was how each company talked about the integration of risk processes in setting compensation policies - not simply how much of a compensation package was 'at risk' but how the compensation package took into account risk assessment, management and outcomes. The following observation was made from this qualitative search. ${ }^{5}$ Before the crisis, most all of the financial institutions and regional banks specifically identified how risk was taken into account when designing compensation while none of the non-financial companies described in much detail how risk management was considered in setting compensation. After the crisis, all of the financial institutions and regional banks discuss in detail how risk was considered in setting compensation. For non-financial firms, half of them discuss some aspect of how risk was considered in setting compensation, however only one does so thoroughly. This result too is in-line with the FCIC report in that firms did a poor job pre-crisis in linking risk management outcomes with compensation design.

The final issue examined from study one was the focus on strategies aimed to improve the bottom line and which overshadowed sound risk management. To explore this relationship, I searched for the words 'growth' and 'return' in the firm's proxy statements. After getting a count of these words, a ratio of how often the word 'risk' appeared in relation to these two words was calculated. The ratios are graphed in Figure 2. As can be seen in the graphs, risk is talked about more than return after the crisis compared to before. A ratio of less than one means that the firm talked about return more than risk. An interesting take-away appears when looking at the magnitude of the ratios. For financial institutions and regional banks, four of the six firms mention risk over two times more than return after the crisis, with one of those firms mentioning risk over four times as much, and one firm mentioning it almost three times as much. While for non-financial firms, the use of risk compared to return increases post crisis; four of the six firms use risk and return about the same number of times while two talk about risk less than return. These results, particularly for financial firms, appear to be in line with the FCIC report. Almost all of the firms focus more on return and growth prior to the crisis than risk.

\section{GENERAL DISCUSSION}

The purpose of this study has been twofold. First, I wanted to identify the contributing factors or risk management failure leading up to, and during, the 
financial crisis. Drawing upon the FCIC report, five 'themes' emerged from the passages which mention risk management. Second, I wanted to explore, in a very general sense, the extent to which failures identified at the large financial companies at the center of the crisis, had been remedied immediately after the crisis by all types of firms, not just financial firms.

The analyses uncover several areas for firms to consider as they look to improve their risk management. These suggestions are aimed largely at nonfinancial institutions. The reason being that following the crisis, regulatory bodies in the U.S. issued a number of regulations and specific guidance for risk-reporting aimed at financial institutions and regional banks. For instance, in response to risk management failures the government passed legislation like the Dodd-Frank Wall Street Reform and Consumer Protection Act (2010) aimed at reducing future risks to the financial industry. This legislation was largely aimed at the risk management at financial institutions, giving oversight authority to the Federal Reserve.

In addition to Dodd-Frank regulations, the SEC approved the Proxy Disclosure Enhancement (2009) guidelines designed to enhance disclosures about risk in the firm's proxy filings. In the new guidelines, firms are required to make some reference to compensation design and risk, as well as the role the Board of Directors plays in risk oversight. While helpful, the SEC rules do not require behavioral changes, only the disclosure of additional information. However, given the present analysis, it is apparent that financial firms and regional banks have done a much better job post-crisis in addressing how risk management and risk, in general, figure into the management of the firm. These firms appear to be adhering to the new standards.

While it is clear that financial institutions and regional banks have addressed the shortcomings of risk management found during the financial crisis (likely in response to increased reporting and regulatory requirements), nonfinancial companies appear to have several areas which need improvement. While financial firms seemed to have at least made some aesthetic changes based upon their experiences (I would hesitate to call it learning without more detailed internal information about the processes of the firm), it does not appear that non-financial companies have learned vicariously from the experiences of the financial companies. There are multiple opportunities for non-financial firms to improve upon their risk management processes, which are addressed below. 


\section{Compensation Systems}

Compensation systems are one area that non-financial firms could improve in their pursuit of improved risk management. As suggested by Lam (2014), incentivized performance becomes problematic when the incentives are focused on one dimension of firm performance -- in many instances, stock price. Furthermore, incentives became especially problematic for financial firms when those contracts came with accelerated payout options. These two characteristics, a singular focus on stock price performance and accelerated payout options, made it difficult for managers to focus on the long-term outcomes of risk when making decisions. Recent research has suggested (e.g. Rochette, 2009) and empirically found (e.g. Grace et al., 2015) that one way to improve risk management is to tie incentives to risk management objectives in addition to other outcomes.

For firms seeking to improve the alignment of their compensation with risk management, first managers need to identify key performance indicators (KPI) that will either A) be impacted by the risk management process, or B) be reflective of success for key risk management activities. Each KPI is developed by first establishing the performance objective, then identifying the appropriate performance measure for the objective, and finally, developing the KPI.

Once KPIs have been established, compensation needs to be explicitly linked to each KPI. As an example, one of the key risk factors identified by John Deere in its 2010 financial report, which may materially impact the firm's financial performance, is stated as "John Deere's business results depend largely on its ability to develop, manufacture and market products that meet customer demand." As a result, one of Deere's performance objectives might be: to have all customers rate their satisfaction with the quality of Deere products as the best in the industry - this would seem to substantially reduce the risk that customers are dissatisfied with Deere products. The performance measure could be: the percentage of customers that rate Deere products as highest quality in the industry. The KPI could then be: $90 \%$ of customers ranking Deere as having the highest quality products in the industry each quarter/half-year/ etc. If Deere is hitting this KPI, they in theory, would reduce one of the key risks that could materially impact their business. The CEO's compensation would then be tied to this KPI. (To be clear, this is just an illustrative example using a company that is highly visible. I am not suggesting that Deere is not using KPIs tied to risk factors when it comes to designing executive compensation.)

As Lam (2014) has suggested, compensation must not be aligned with simple measures of return, but with long-term risk-adjusted return hurdles with appropriate 
vesting periods. Additionally, plans should continue to reward management for stability, continuity, and comparative performance to incentivize a long-term view when making decisions involving risk. Also, organizations may consider clawback policies for compensation when management knowingly engages in harmful behavior or exceeds the risk appetite of the firm. Eliminating golden parachutes and sizeable compensation packages upon termination for poor performance, as a result of exceeding pre-specified risk thresholds, may also encourage executives to act in a responsible way as they consider risk. Lastly, management also needs to be mindful that their compensation plans, while incorporating the above, still encourage innovation and capital investment to increase long-term value. This can be done using risk-adjusted hurdle rates to determine which projects or strategies are in-line with the firm's stated level of risk tolerance.

\section{Human Resource Allocation}

In terms of resource inadequacies, there are several areas for improvement. First, managers need to staff the risk management function with human capital which has the appropriate certifications and qualifications given the business of the firm, and second, provide adequate funding for the risk management function to execute on its risk management strategy. Risk managers should be chosen based upon their track record, their experience, their knowledge of the industry and their knowledge of the business. As risk management has become more important as a result of recent crises, universities are offering more risk management degrees and professional organizations are offering special certificates for risk management certifications. For example (at the time of the writing of this paper), New York University offered a Masters Degree in Risk Management in their Global Degree Department in the business school; John Hopkins University offered a Masters Degree in ERM; and many other universities (e.g., University of Connecticut) have financial risk management programs. Other universities, such as Stanford University, offer an online program for a Risk Management Certificate through their Center for Professional Development. Non-university entities like the National Alliance for Insurance Education and Research also offered a class-based/seminar-based Certified Risk Management (CRM) program.

In addition to education-based training, many professional organizations offer certification tests for risk managers in specific functional fields. For example, the Project Management Institute offers a Risk Management Professional (RMP) certification test; the American Hospital Association offers a Certified Professional 
Healthcare Risk Manager (HRM) designation; and the Risk and Insurance Management Society offers a Certified Risk Management Professional (CRMP) credential test.

Thus, in theory, these programs should make finding risk management professionals easier and more cost efficient. Just as you would not have a Chief Financial Officer without financial or accounting expertise, firms should not have a Chief Risk Officer without substantive risk management expertise. Ideally, firms would select risk managers that are educated in the risk management field, has experience managing risk in the specific functional area, has the appropriate designation (for instance, a risk manager which is certified as a Healthcare Risk Manager is probably not the appropriate manager to work as a risk management professional in a bank), and is credentialed.

\section{Financial Resource Allocation}

In addition to human capital, firms need to be more diligent about allocating financial resources to their risk management functions. By having better risk management systems as mentioned above, identifying the scope of the risk management program should be easier for management. With a better understanding of the scope of the risks which need to be treated, managers can make more accurate budgets. Instead of taking shots in the dark, managers can develop reasonable and accurate figures for risk management expenses. In addition to allocating resources to the risk management function, firms should also build up financial slack buffers that insulate the firm from risk events. There is considerable evidence that having cash on hand is not inefficient, but can drive firm value. Kim and Bettis (2014) show that large cash holdings, beyond what is needed for transactional purposes, have a positive impact on firm value. Similarly, Deb, David and O'Brien (2017) found that cash creates shareholder value when it is used for adapting to uncertainty, such as by firms operating in competitive, research-intensive or growth-oriented industries. Thus, the adequate level of financial resources for risk management is dependent on the firm, its existing resource position, and industry conditions. While the state of financial resource allocation was not examined specifically in this study, future work should explore this domain.

\section{Risk vs. Return}

Additionally, managers need to align their risk management performance with their corporate objectives and goals. Managers may want to consider using 
objectives that are not purely based on financial performance, such as growth and returns. For instance, $\mathrm{S} \& \mathrm{P}$ has begun to rank firms on their risk management activities. Depending upon the industry, firms may want to consider pursuing a particular level of risk management ranking as a stated year-end objective. If firms want to continue incorporating financial metrics they could incorporate risk by utilizing risk-adjusted performance outcomes. Firms may also want to consider developing performance indicators which address the key risks they disclose in their annual reports (please see the example above in the Compensation Systems section for an example). A focus on reducing the key risk indicators could be considered in addition to purely performance-based measures.

It is important to keep in mind that the suggestions mentioned here are not exhaustive and are but a few of the many things management can do to improve risk management. It is important to remember that risk management should be an integral part of a firm's strategy. Risk management should be incorporated into the strategy-making process so that it is not subjugate to business objectives, but instead helps the firm accomplish its long-term goals and objectives.

\section{Limitations and Future Research}

As with all research there are limitations associated with this study. First, the most obvious is that this study relies on a commission's report which is based on first-hand accounts of the events leading to the crisis. Thus, there is no ability to control for any biases or omissions of the commission. However, the creation of the commission was done in a way which sought to limit this concern from the outset. The commission was constructed as a bi-partisan effort and was given unprecedented access to information sources that any researcher studying the crisis will not be able to collect on their own. Furthermore, while the research presented here is based on the report of a single commission, it bears noting that the commission's work is the amalgamation of over 700 first-hand accounts, millions of pages of text and research, and countless hours of public scrutiny. Nevertheless, this limitation should be taken into account when interpreting the findings of this study.

Second, the methodology incorporated in Study 2 of the current research may also be considered a limitation. The author purposefully selected a limited sample of highly visible and recognizable firms to perform the exploratory analysis. Given the exploratory nature of the study, it was not the intent to collect a large number of firms and employ econometric analysis. Highly visible firms are typically more heavily scrutinized by the public than are low visibility firms. The firms that I have 
chosen, I have reasoned, would be the most susceptible to pressure to improve their risk management activities following a crisis such as the financial crisis. Investors, and the public alike, want to know what these large firms are doing to ensure the safety of investments and the economy in response to what was seen in the financial industry. Thus, if these firms had not changed their approach to risk management, it is highly likely that other firms facing less scrutiny would have done so.

Finally, findings of Study 1 are based solely upon the experiences of financial companies during the crisis. The conclusions of Study 2 are based upon an analysis of non-financial companies. As a result, this may represent a threat to the external validity of the results. The purpose of applying lessons from financial companies to non-financial companies was to highlight the clear shortcomings in risk management at firms' where risk management is a critical factor in achieving success, and using this as a platform for all firms to build and learn from in the future. This is similar to the 'strategic benchmarking' concept (Drew, 1997), where firms find examples of other firms who have capabilities or competencies in a particular area (such as risk management), and benchmark their own activities in this area versus the activities of the selected firms that have built those capabilities. In this instance, the financial firms should have capabilities and competencies in risk management. Non-financial firms, then, should be able to learn from the strategies and activities (or lack thereof) of these financial firms. Ultimately however, in choosing the method and a limited sample, the generalizability of the conclusions reached in this study should be considered when interpreting the results. Attempts were made to ensure rigor and validity in both studies, however, stricter protocols for qualitative research could be argued for.

With respect to future research, there are several avenues to pursue. From a theoretical perspective, there is still much we do not know about what contributes to risk management success or failure. Just by looking at the shortcomings of risk management during the financial crisis there seems to be several management-related research themes. First, it might be instructive to understand what characteristics of executives are associated with better or worse risk management. An upper echelons perspective would be informative in this area, exploring biases, personalities and other demographic characteristics that may be associated with risk management. Additionally, research on corporate governance is a natural fit with the risk management literature. Exploring the impact of board composition, executive compensation and other governance characteristics on risk management systems might be informative.

From a methodological perspective, future research might focus on more 
qualitative studies. One of the avenues mentioned briefly in the present paper is the role of risk communication in the risk management process. Perhaps exploring how executives and risk managers are interacting and communicating can give us more insight in to why the risk management process can be so difficult for firms. Finally, future quantitative research could focus on themes touched upon in this study related to resource allocation, executive compensation and risk management performance. However, before research on these areas can commence, better measures of risk management outcomes are necessary -- this too could be an area for theoretical development.

Finally, I would be remiss to not mention that the items identified in this paper were occurring against a backdrop that included a very weak institutional environment. The institutional environment (e.g., Scott and Davis, 2007) as described in the management literature, provides a backdrop for firm behavior. The institutional environment embodies both informal and formal pressures exerted on firms by outside influences. The FCIC report consistently mentioned the general weakness of the institutional environment before the crisis. This was apparent in two areas -- weak regulating bodies not promoting best practices in risk management, and an overreliance on institutionalized practices such as letting firms police themselves. Whilst a more detailed discussion is beyond the scope of the current paper, they need to be mentioned.

\section{CONCLUSION}

To conclude, the goal of this paper was to highlight the shortcomings of financial firms' risk management activities during the financial crisis in the hopes of uncovering areas for improvement for all firms regardless of industry. The assumption is that risk management failures occur because organizations do not have (sophisticated) risk management systems in place. This research suggests that is not entirely true. In the case of many of the financial firms that failed, most had "sophisticated" risk management systems. To make matters worse, many thought their systems were strong. The failures of these institutions help us understand that while a system might be in place, the system needs to be constructed such that the fundamental elements like resources, incentives, corporate objectives and managers, must be aligned. While this may seem like a relatively basic idea, it has escaped many companies.

The FCIC's report on the financial crisis provides a wealth of insight and information. Yet the implications for risk management as a result of the commission's 
work has not yet been fully understood. It is easy to look back in hindsight and point out all of the missteps which occurred. The foresight required to steer clear of all possible sources of risk during the crisis was probably outside the grasp of any human being. Be that as it may, I have identified a number of failures that were within the grasp of managers and boards of directors. Successful risk management was not impossible. Perhaps after exploring the reasons for failure in more detail, managers can be more cognizant of these issues in the future.

\section{ENDNOTES}

1. The commission was an independent group of individuals, consisting of 10 private citizens that had experience across a number of different fields related to different aspects of the crisis (e.g. banking, housing, finance, etc.). The members of the commission were elected by both parties in Congress to ensure bi-partisan conclusions (a majority opinion was reached although there were some members who provided a minority opinion).

2. This article is based upon, to a large extent, information which is contained in the FCIC's report. Thus, statistics, quotes, and paraphrased comments not cited directly in the document are sourced from the FCIC's report which is cited in the references section above.

3. The list of passages presented in Appendix A is not exhaustive, i.e. is not the complete list of passages used for the analysis. A complete list of passages can be obtained from the author.

4. The specific data points are not presented quantitatively in the paper but are available upon request from the author.

5. See note 4.

\section{REFERENCES}

Angriawan, A. \& Abebe, M. (2011). Chief Executive Background Characteristics and Environmental Scanning Emphasis: An Empirical Investigation. Journal of Business Strategies, 28(1), 1-22.

Beasley, M., Clune, R. \& Hermanson, D. (2005). Enterprise Risk Management: An Empirical Analysis of Factors Associated with the Extent of Implementation. Journal of Accounting and Public Policy, 24, 521-531.

Bebchuk, L., Cohen, A., \& Spamann, H. (2010). The Wages of Failure: Executive Compensation at Bear Stearns and Lehman 2000-2008. Yale Journal of Regulation, 27, 257-265. 
Carley, K. (1993). Coding Choices for Textual Analysis: A Comparison of Content Analysis and Map Analysis. In P. Marsden (Editor), Sociological Methodology (pp. 75-126). Oxford: Blackwell.

Chapman, R. (2011). Simple Tools and Techniques for Enterprise Risk Management.

New York: West Sussex, UK: John Wiley and Sons, Ltd.

Clarke, C. \& Varma, S. (1999). Strategic Risk Management: The New Competitive Edge. Long Range Planning, 32(4), 414-424.

Deb, P., David, P., \& O'Brien, J. (2017). When is Cash Good or Bad for Firm Performance? Strategic Management Journal, 38(2), 436-454.

Drew, S. (1997). From Knowledge to Action: The Impact of Benchmarking on Organizational Performance. Long Range Planning, 30(3), 427-441.

Duriau, V., Reger, R., \& Pfarrer, M. (2007). A Content Analysis of the Content Analysis Literature in Organization Studies. Organizational Research Methods, 10(1), 5-34.

Farrell, G., \&Hansen, B. (2008, April 9). Stock May Fall but Execs’ Pay Doesn’t. USA Today. Retrieved from http://usatoday30.usatoday.com/money/companies/ management/2008-04-09-ceo-pay_N.htm

Financial Crisis Inquiry Commission. (2011). The Financial Crisis Inquiry Report:

Final Report of the National Commission on the Causes of the Financial and Economic Crisis in the United States.Washington, D.C.: U.S. Government Printing Office. (Available from https://fcic.law.stanford.edu)

Frame, J. (2003). Managing Risk in Organizations. San Francisco: Jossey-Bass.

Fraser, J. \& Simkins, B. (2010). Enterprise Risk Management: An Introduction and Overview. In J. Fraser \& B. Simkins (Eds), Enterprise Risk Management: Today's Leading Research and Best Practices for Tomorrow's Executives (pp. 3-17). Hoboken, NJ: John Wiley and Sons.

Gephart, R. (1993). The Textual Approach: Risk and Blame in Disaster Sensemaking. Academy of Management Journal, 36(6), 1465-1514.

Grace, M., Leverty, J., Phillips, R., \& Shimpi, P. (2015). The Value of Investing in Enterprise Risk Management. The Journal of Risk and Insurance, 82(2), 289316.

Hambrick, D. \& Mason, P. (1984). Upper echelons: The Organization as a Reflection of its Top Managers. Academy of Management Review, 9(2),193-206.

Hayward, M. \& Hambrick, D. (1997). Explaining the Premiums Paid for Large Acquisitions: Evidence of CEO Hubris. Administrative Science Quarterly, 42(1), 103-127. 
Hoyt, R. \& Liebenberg, A. (2011). The value of Enterprise Risk Management. The Journal of Risk and Insurance, 78(4), 795-822.

Hubbard, D. (2009). The Failure of Risk Management: Why it's Broken and How to Fix it. Hoboken, NJ: John Wiley and Sons.

Huber, G. (1991). Organizational Learning: The Contributing Processes and the Literatures. Organization Science, 2(1), 88-115.

Jickling, M. (2009). Causes of the Financial Crisis (R40173). Washington, DC: Congressional Research Service. Retrieved from: http://digitalcommons.ilr. cornell.edu/key_workplace/600

Kim, C. \& Bettis, R. (2014). Cash is Surprisingly Valuable as a Strategic Asset. Strategic Management Journal, 35(13), 2053-2063.

Lam, J. (2014). Enterprise Risk Management: From Incentives to Controls. John Wiley and Sons.

Liebenberg, A. \& Hoyt, R. (2003). The Determinants of Enterprise Risk Management: Evidence from the Appointment of Chief Risk Officers. Risk Management and Insurance Review, 6(1), 37-52.

Madsen, P. \& Desai, V. (2010). Failing to Learn? The Effects of Failure and Success on Organizational Learning in the Global Orbital Launch Vehicle Industry. Academy of Management Journal, 53(3), 451-476.

Miller, K. (1998). Economic Exposure and Integrated Risk Management. Strategic Management Journal, 19, 497-514.

Miller, K. \& Waller, H. (2003). Scenarios, Real Options and Integrated Risk Management. Long Range Planning, 36, 93-107.

Rochette, M. (2009). From Risk Management to ERM. Journal of Risk Management in Financial Institutions, 2(4), 394-408.

Scott, R. \& Davis, G. (2007). Organizations and Organizing: Rational, Natural and Open System Perspectives. Upper Saddle River, NJ: Pearson Prentice Hall.

Shenkir, W., Barton, T., \& Walker, P. (2010). Enterprise Risk Management. In J.

Fraser \& B. Simkins (Eds), Enterprise Risk Management: Today's Leading Research and Best Practices for Tomorrow's Executives (pg. 441-463).Hoboken, NJ: John Wiley and Sons.

Shortreed, J. (2010). ERM Frameworks. In J. Fraser and B. Simkins (Editors), Enterprise Risk Management: Today's Leading Research and Best Practices for Tomorrow's Executives (pg. 97-123). Hoboken, NJ: John Wiley and Sons.

Tang, Y., Qian, C., Chen, G. \& Shen, R. (2014). How CEO Hubris Affects Corporate Social (Ir)Responsibility. Strategic Management Journal, 36(9), 1338-1357. 
Tuckman, B. (2016). Derivatives: Understanding Their Usefulness and Their Role in the Financial Crisis. Journal of Applied Corporate Finance, 28(1), 62-71.

Vo, L. (2015). Lessons From the 2008 Global Financial Crisis: Imprudent Risk Management and Miscalculated Regulation. Journal of Management Sciences, 2(1), 205-222.

\section{BIOGRAPHICAL SKETCH OF AUTHOR}

Corey J. Fox is an Assistant Professor of Management in the McCoy College of Business at Texas State University. He received his PhD in Business Administration from Oklahoma State University. His current research focuses on issues related to risk and risk management in organizations, corporate resource allocation decisions, and corporate citizenship. His work has been published in such outlets as the Journal of Managerial Issues and Strategic Organization. 


\title{
Appendix A \\ Example Passages
}

\begin{abstract}
No Substantive Information
Doing so required research into broad and sometimes arcane subjects, such as mortgage lending and securitization, derivatives, corporate governance, and risk management. To bring these subjects out of the realm of the abstract, we conducted case study investigations of specific financial firms - and in many cases specific facets of these institutions - that played pivotal roles. (FCIC: XII)

JP Morgan reported that large pension funds and some smaller Asian central banks were reducing their exposures to Lehman, as well as to Merrill Lynch. And Citigroup requested a $\$ 3$ to $\$ 5$ billion "comfort deposit" to cover its exposure to Lehman, settling later for $\$ 2$ billion. In an internal memo, Thomas Fontana, the head of risk management in Citigroup's global financial institutions group, wrote that "loss of confidence [in Lehman] is huge at the moment." (FCIC: 328 )

Geithner would ask E. Gerald Corrigan, the Goldman Sachs executive and former New York Fed president who had co-chaired the Counterparty Risk Management Policy Group report, to form an industry group to advise on information needed from a troubled investment bank. (FCIC: 329)

\section{Risk Management Process Failures}

Passage 1:

(Murray) Barnes (the Citigroup risk officer assigned to the CDO business) told the FCIC that Citigroup's risk management tended to be managed along business lines, noting that he was only two offices away from his colleague who covered the securitization business and yet didn't understand the nuances of what was happening to the underlying loans. (FCIC: 262)

\section{Passage 2:}

Financial institutions and credit rating agencies embraced mathematical models as reliable predictors of risks, replacing judgment in too many instances. Too often, risk management became risk justification. (FCIC: XIX) Passage 3:

Citigroup's risk management function was simply not very concerned about housing market risks. According to (Charles) Prince, (David) Bushnell (the Chief Risk Officer) and others told him, in effect, 'Gosh, housing prices would have to go down $30 \%$ nationwide for us to have.....problems,' and that has never happened since the Depression.' Housing prices would be down much less than $30 \%$ when Citigroup began having problems because of write-downs and the liquidity puts it had written. (FCIC: 262)

Passage 4:

Although the firm had proclaimed that "Risk Management is at the very core of Lehman's business model," the Executive Committee simply left its risk officer, Madelyn Antoncic, out of the loop when it made this investment. (FCIC: 177)
\end{abstract}

\section{Support System (Compensation) Failures}

\section{Passage 5:}

She (FDIC Chairperson Sheila Blair) concluded, "The crisis has shown that most financial institution compensation systems were not properly linked to risk management. Formula- driven compensation allows high short-term profits to be translated into generous bonus payments, without regard to any longer-term risks."

(FCIC: 64)

Passage 6:

The Commission concludes that some large investment banks, bank holding companies, and insurance companies, including Merrill Lynch, Citigroup, and AIG, experienced massive losses related to the subprime mortgage market because of significant failures of corporate governance, including risk management. Executive and employee compensation systems at these institutions disproportionally rewarded short-term risk taking. (FCIC: 279)

Passage 7:

Lehman's failure resulted in part from significant problems in its corporate governance, including risk management, exacerbated by compensation to its executives and traders that was based predominantly on shortterm profits. (FCIC: 343 )

*Portions in parentheses and italics have been added for context while bold font has been added to highlight the term 'risk management' 


\section{Resource Allocation Failures}

Passage 8:

In the meeting with (Robert) Willumstad (the chairman of $A I G$ 's board of directors), the auditors were broadly critical of (Martin) Sullivan (CEO of $A I G$ ); (Steven) Bensinger (CFO of $A I G$ ), whom they deemed unable to compensate for Sullivan's weaknesses; and (Robert) Lewis (Chief Risk Officer at AIG), who might not have "the skill sets" to run an enterprise-wide risk management department. (FCIC: 273)

Passage 9:

The SEC's inspector general later criticized the regulators, writing that they did not push Bear to reduce leverage or "make any efforts to limit Bear Stearns' mortgage securities concentration," despite "aware[ness] that risk managementof mortgages at Bear Stearns had numerous shortcomings, including lack of expertise by risk managers in mortgage backed securities" and "persistent understaffing; a proximity of risk managers to traders suggesting a lack of independence; turnover of key personnel during times of crisis; and the inability or unwillingness to update models to reflect changing circumstances.”(FCIC: 283)

\section{Passage 10:}

Management told the board that Fannie's risk management function had all the necessary means and budget to act on the plan. Chief Risk Officer Dallavecchia did not agree, especially in light of a planned $16 \%$ cut in his budget. In a July 16, 2007, email to CEO Mudd, Dallavecchia wrote that he was very upset that he had to hear at the board meeting that Fannie had the "will and the money to change our culture and support taking more credit risk," given the proposed budget cut for his department in 2008 after a $25 \%$ reduction in headcount in 2007. (FCIC: 182)

\section{Top Management Failures}

\section{Passage 11:}

On December 5th...Sullivan boasted on another conference call about AIG's risk management systems and the company's oversight of the subprime exposure: "The risk we have taken in the U.S. residential housing sector is supported by sound analysis and a risk management structure. . . .we believe the probability that it will sustain an economic loss is close to zero...We are confident in our marks and reasonableness of our valuation methods." (FCIC: 272)

\section{Passage 12:}

Merrill's then-CFO Jeffrey Edwards indicated that the company's results would not be hurt by the dislocation in the subprime market, because "revenues from subprime mortgage-related activities comprise[d] less than $1 \%$ of our net revenues" over the past five quarters, and because Merrill's "risk management capabilities are better than ever, and crucial to our success in navigating turbulent markets." (FCIC: 258)

\section{Passage 13:}

The company's auditors, PricewaterhouseCoopers (PwC), who were apparently also not aware of the collateral requirements, concluded that "the risk of default on [AIG's] portfolio has been effectively removed and as a result from a risk management perspective, there are no substantive economic risks in the portfolio and as a result the fair value of the liability stream on these positions from a risk management perspective could reasonably be considered to be zero." (FCIC: 267)

\section{Objective Tradeoff Failures}

\section{Passage 14:}

"Plans to meet market share targets resulted in strategies to increase purchases of higher risk products, creating a conflict between prudent credit risk management and corporate business objectives," the Federal Housing Finance Agency (the successor to the Office of Federal Housing Enterprise Oversight) would write in September 2008 on the eve of the government takeover of Fannie Mae. (FCIC: 179)

\section{Passage 15:}

(Murray) Barnes's (Citigroup risk officer assigned to the CDO business) decision to increase the CDO risk limits was approved by his superior, Ellen Duke. Barnes and Duke reported to David Bushnell, the chief risk officer. Bushnell-whom (Chuck) Prince (one-time CEO at Citigroup) called "the best risk manager on Wall Street"told the FCIC that he did not remember specifically approving the increase but that, in general, the risk management function did approve higher risk limits when a business line was growing. He described a "firmwide initiative" to increase Citigroup's structured products business. (FCIC: 261) 
Figure 1

Risk Management Counts

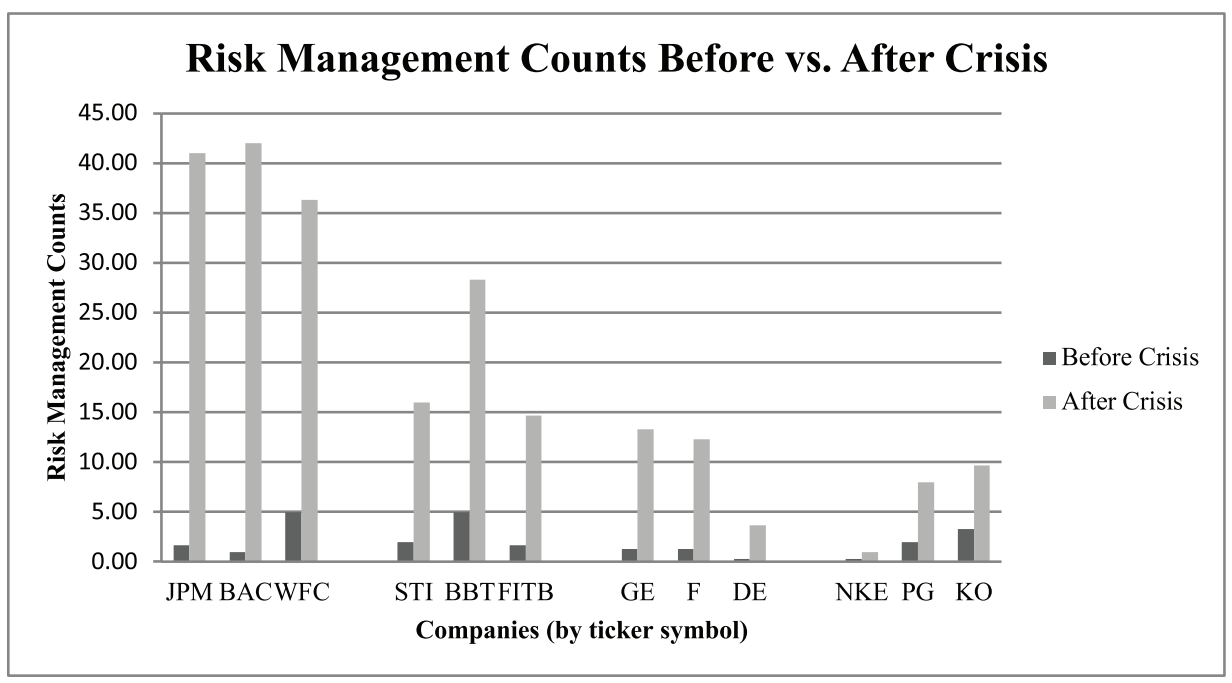

Figure 2

Risk/Return Ratios

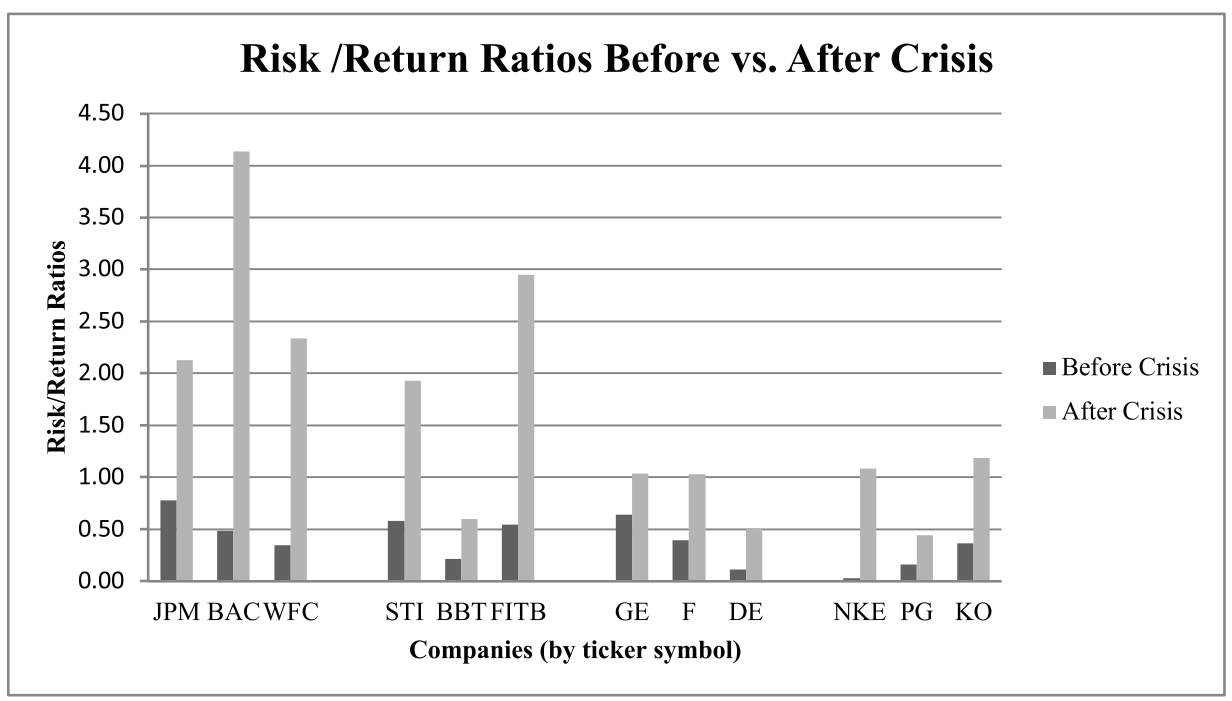

